\title{
MODELS AND PROCEDURES FOR ELECTRIC ENERGY DISTRIBUTION PLANNING. A REVIEW
}

\author{
Rodrigo Sempértegui, Joaquin Bautista, Robert Griño Cubero, Jordi Pereira \\ semperte@ioc.upc.es, bautista@oe.upc.es, grino@ioc.upc.es, pereira@oe.upc.es \\ Departamento de Organización de Empresas \\ Instituto de Organización y Control de Sistemas Industriales \\ Universidad Politécnica de Catalunya \\ Barcelona - Spain
}

\begin{abstract}
Distribution system planning is a key component to accomplish the service in a fast growing demand market, both from a technical point of view and from the economic costs management. In the near future, electric companies will need faster and cheaper planning tools to evaluate different scenarios and their consequences for the rest of the system and provide their clients whit safe reliable and economic energy. The objective of this paper is to review different articles about this subject trying to continue the previous work from Gonen and Ramírez-Rosado in 1986 (Gönen,1986). Copyright (C) 2002 IFAC
\end{abstract}

Keywords: planning, distribution, optimisation.

\section{INTRODUCTION}

The distribution system planning goal is to assure that a demand growth can be satisfied in an optimal way from the secondary feeders to the substations from where energy must be delivered to the final client economically while complying with several technical specifications. These considerations and several others - like the difficulties to obtain urban soil, aesthetic and ecological considerations - can harden the problem of optimal planning calculus. The people in charge of distribution planning should consider the energy consumption, their geographical location, laws regarding the use of soil plus other aspects to come up with the substations dimensioning and location, the maximum efficiency routes, while minimising the energy loss in the feeders and deployment costs, plus satisfying the reliability of service constraints.

The planners usually divide the planning in several subproblems, which can be efficiently solved by algorithms and procedures already available. The objective is minimising the installation costs of substations and feeders, plus the implied costs associated to maintenance and operation, while satisfying several constraints related to the allowable voltage values, reliability, service maintenance, etc.

As the distribution system related costs constitute an important part of the electric power systems total costs, the need of more rigorous mathematical models and the development of more efficient algorithms is obvious. The final objective should be minimising incurred costs and achieving the desired goals.

The design of electric energy distribution system planning is executed around the existing system using a procedure containing the following steps: demand forecasting and assignment to existing or new areas, location and dimensioning of substations, dimensioning and routing of feeders and distribution networks. Today, and thanks to the computers development, improvements to the proposed plans can be obtained analysing several different 
alternatives by using mathematical models and different optimisation procedures.

\section{MODELS REVIEW}

In this section we will review the published works about growth planning of the distribution systems, as well as different approaches given to this topic in order to know the models, resolution methods and constraints.

Of the works existing about this topic, we have revised the ones which have appeared in specialised journals, as IEEE and IEE.

The models have been classified in accordance to several characteristics such as system treatment, planning horizon and time lapse, methods to handle the problems related with substations and/or feeders consider: costs, location and dimensioning problems, voltage drops and radiality consideration, and finally the proposed mathematical methods to solve them, as suggested by Gönen T. and Ramírez-Rosado in 1986.

\subsection{Handling of the Distribution System.}

From the point of view of how the system is handled, the problem of distribution system planning is usually subdivided in two subproblems, due to their large size. The two subproblems are:

The subproblem of optimal dimensioning and/or location of electric distribution substations [Adams et al. 1984, Adams, Laughton, 1973, Adams, Laughton, 1974, Afuso et al. 1982, Bouchard et al. 1994, Crawford, Holt Jr 1975, Holt Jr, Crawford 1976, Hongwei et al. 1993, Masud 1974, Masud 1978].

The subproblem of dimensioning and/or location of feeders [Adams, Laughton, 1974, Mikic 1986, Wall et al. 1979].

Some researchers try to solve the problem as a sequence of both subproblems, after analysing the location and dimensioning of substations in a first step, the optimal dimensioning and routing from the feeders is calculated. But from a mathematical point of view, this approach does not guarantee us that an optimal solution to the global problem is found, because each subsystem is solved independently and the optimisation of the whole system is not separable in two unrelated subproblems [Skrlec 1996]. The solutions may end up in a local minimum of the separated problems, not reaching the global minimum.

Due to the errors incurred in the separated treatment of both subproblems, and thanks to the development of fast computer systems, nowadays the solution of the whole problem in a single step is devised. This methodology tries to solve together the analysis of location of substations, dimensioning of substations and feeders and finally distribution networks routing [Aoki et al. 1990, Blanchard et al. 1996, Boardman, Meckiff 1985, Brauner, Zobel 1994, El-Kadi 1984,
Fawzi et al. 1983, Gönen, Foote 1981, Gönen, Foote 1982, Gönen 1986, Hindi, Brameller 1977, Hsu, Chen 1990, Lin et al. 1998, Miranda et al. 1994, Nara et al. 1991, Nara et al. 1992, Ponnavaikko, Prakasa 1981, Quintana et al. 1993, Ramírez-Rosado, BernalAgustin 1998, Ramírez-Rosado et al. 1999, RamírezRosado., Gönen 1991, Sun et al. 1982, Tang 1996, Thompson, Wall 1981, 70].

\subsection{Planning horizon.}

In the revised models, the plan duration can be defined as simple (one step) or as multiple (several steps).

The simple step models - usually called static models - consider that the energy demand will be static during the horizon of planning. There is no analysis of the demand growth, and there is no need to study the possible changes in substation and feeders installations through the planning period. Usually the horizon considered is one year [Adams, Laughton, 1974, Aoki et al. 1990, Crawford, Holt Jr 1975, ElKadi 1984, Fawzi et al. 1983, Gönen, Foote 1981, Hindi, Brameller 1977, Holt Jr, Crawford 1976, Masud 1974, Sun et al. 1982, Thompson, Wall 1981, Wall et al. 1979].

In the multiperiod case researchers have opted for two methodologies:

a) A pseudodynamic one based on solving a group of problems with a single period, where each period output is the next period input plus a demand growth forecasting. As in the previous case, the optimal solution to these subproblems might be suboptimal for the whole problem, as the decisions taken in a step of the resolution cannot be modified afterwards.

b) A dynamic methodology, known as dynamic models, which try to solve the multi-period distribution system planning in a single procedure, and the building decisions for. In the dynamic methodology the decision building for several years or steps are optimised in a single procedure.

Several efforts have been made to develop more sophisticated methods to solve the multi-period distribution system planning known as dynamic models [Adams et al. 1984, Adams, Laughton, 1973, Adams, Laughton, 1974, Afuso et al. 1982, El-Kadi 1984, Gönen, Foote 1982, Gönen 1986, Masud 1978, Sun et al. 1982].

\subsection{Voltage losses and radiality considerations}

Both considerations have a great deal of importance in planning. When planning the interested is centered in obtaining a radial network of feeders, because radial networks are usually cheaper and easier to administrate, while the voltage losses are restricted by technical considerations, usually represented as a minimum allowable voltage. 
The radiality has not been included in some of the studied mathematical methods [Adams, Laughton, 1974, Gönen, Foote 1981, Gönen, Foote 1982, Sun et al. 1982].

Some revised models [Adams, Laughton, 1974, ElKadi 1984, Gönen, Foote 1981, Gönen, Foote 1982, Hindi, Brameller 1977, Sun et al. 1982, Thompson, Wall 1981, Wall et al. 1979] do not include any constraint related to the minimum allowable voltage, thus creating solutions which may not be valid for real situations, as they may not deliver energy in the needed conditions.

\subsection{Mathematical models used.}

The problem could be naturally seen as a non-linear combinatorial optimisation problem, but many researchers use linear approximations to reduce the problem. Then, the problem can be seen as a mixed integer linear programming problem [Adams et al. 1984, Adams, Laughton, 1974, Afuso et al. 1982, Aoki et al. 1990, El-Kadi 1984, Fawzi et al. 1983, Gönen, Foote 1981, Gönen, Foote 1982, Gönen 1986, Hindi, Brameller 1977, Masud 1974, Masud 1978, Nara et al. 1991, Ramírez-Rosado., Gönen 1991, Sun et al. 1982, Thompson, Wall 1981, Wall et al. 1979], and solved using the available procedures based on the simplex method. The references [Adams et al. 1984, Adams, Laughton, 1973, Afuso et al. 1982] use a dynamic programming model and [Crawford, Holt Jr 1975, Holt Jr, Crawford 1976] use graph theory related models, and solve the problem combining shortest path algorithms and transportation algorithms. It's interesting to remark that many of the revised models used for practical problems use employ Branch and Bound algorithm as their solution technique [Adams et al. 1984, Afuso et al. 1982, Fawzi et al. 1983, Gönen, Foote 1982, Hindi, Brameller 1977, Sun et al. 1982, Thompson, Wall 1981, Wall et al. 1979]. The models developed in [Adams, Laughton, 1974, Gönen, Foote 1981, Gönen, Foote 1982, Gönen 1986, Ramírez-Rosado., Gönen 1991] use straight mathematical programming formulations.

In the reviewed papers from the last years, there is a tendency to use evolutionary algorithms [Bouchard et al. 1994, Lin et al. 1998, Miranda et al. 1994, Ramírez-Rosado, Bernal-Agustin 1998, Neimane, Andersson 1999, Skrlec 1996] and expert systems [Chen, Hsu 1989, Hsu, Chen 1990, Wong, Cheung 1987, Dueire, Carvalho 1996, Tumazos 1997] as solution procedures, obtain which have achieved good results with these techniques.

Table I is presented as an annex, there the characteristics of each reviewed work is shown.

\section{CONCLUSIONS}

From the review we can obtain these conclusions:
- Due to the problem complexity, the model will always be approximated to their real counterparts.

- Most reviewed models do not include the fixed costs from the feeders.

- Many models have poor representations of the feeders, usually linearizing the losses in a single step.

- The linearization of voltage losses does not reflect the real problem.

- Most models do not consider or badly treat the voltage loss as a constraint giving non applicable results in some cases.

- Many models do not consider the demand growth on the studied period.

- Some models consider a uniform growth of the demand on the whole geographical area of study.

- Reliability is badly considered.

- A topic still not treated is the sensibility analysis on the planned system expansion to the changes in the demand forecasting. The forecasting of the demand depends on several factors and is not usually verified. More efficient procedures, including sensibility analysis would provide a method allowing a better consideration of alternatives.

- In the recent works, the greatest effort has been the development of better model approximations for solving via Artificial Intelligence procedures. Researchers involved in these developments consider that those methods are the fittest for the problem characteristics and hardness.

- Many works have only academic interest, and few have been applied to real life problems.

- Some researchers consider fuzzy formulations as a way to stop resource wastes. The definition of good levels of truth and falseness, as well as tolerable constraint violations must be defined.

- There are no works regarding the distribution system planning of urban areas.

\section{REFERENCES}

Adams R.N., Afuso A., Rodríguez A., Peréz V., A Methodology for Distribution System Planning, 8th Power Systems Computation Conference, Finland 19th-24th August 1984, 1984

Adams R.N., Laughton M.A., A Dynamic Programming netword flow procedure for distribution system planning, Procc. 8th Power Industry Computer Application (PICA) Conference Minneapolis USA 3th-6th June 1973, 1973, pp.348-354.

Adams R.N., Laughton M.A., Optimal Planning of Networks Using Mixed-Integer Programming, Proc. IEE, 121, 2, 1974, pp.139-148.

Afuso A., Geréz V., Rodríguez A., And Integrated System for distribution planning, Procc. 4th IEEE International Sympoosium on Large Engieering Systems, Canada, 9th-11th June 1982, 1982.

Aoki K., Nara K., Satoh T., Kitagawa M., Yamanaka K., New Aproximate Optimization Method for Distribution System Planning, IEEE Trans. Power System, 5, 1, 1990, pp.126-132. 
Blanchard M., Delorme L., Simard C., Nadeau Y., Experience with Optimization Software for Distribution System Planning, IEEE Trans. Power System, 11, 4, 1996, pp.1891-1898.

Boardman J.T., Meckiff C.C., A Branch and Bound Formilation to an Electricity Distribution Planning Problem, IEEE Trans. PAS, 104, 8, 1985, pp.2112-2118

Bouchard D.E., Salama M.M.A., Chikhani A.Y., Optimal Distribution Feeder Routing and Optimal Substation Sizing and Placement Using Evolutionary Strategies, IEEE, 1994, pp.661664.

Brauner G., Zobel M., Knowledge Based Planning of Distribution Networks, IEEE Trans. Power System, 9, 2, 1994, pp.942-948.

Cannas B., Celli G., Optimal MV Distribution Networks Planning Whit Heuristic Techniques, IEEE, 1999, pp.995-1000.

Carneiro M., França P.M., Silveira P.D., Long-Range Planning of Power distribution systems: primary networks, Electric Power Systems Research, 1993, pp.223-231.

Carvalho P.M.S., Ferrerira L.A.F.M., Lobo F.G., Barruncho L.M.F., Distribution Network Expansion Planning Under Uncertasinty: A Hedging Algorithm in an Evolutionary Approach, IEEE Trans. Power Delivery, 15, 1, 2000, pp.412-416.

Chen J., Hsu Y., An Expert System for Load Allocation in Distribution Expansion Planning, IEEE Trans. Power Delivery, 4, 3, 1989, pp.1910.-1917.

Crawford D.M., Holt Jr S.B., A Mathematical Optimization Technique for locating and Sizing Distribution Substations, and Deriving Their Optimal Service Areas, IEEE Trans. PAS, 94, 2, 1975, pp.230-234.

El-Kadi M.A., Computer-Aided Planning of Distribution Substations and Primary Feeders, IEEE Trans. PAS, 103, 6, 1984, pp.1183-1189.

Fawzi T.H., Ali K.F., El-Sobki S.M., A New Planning Model For Distributionm Systems, IEEE Trans. PAS, 102, 9, 1983, pp.3010-3017.

Gönen T., Foote B.L., Distributions System Planning using Mixed-Integer Programming, IEE Proc-C, 128, 2, 1981, pp.70-79.

Gönen T., Ramírez-Rosado I., Review of Distributions System Planning Models: a model for optimal multi-stage planning, IEE Proc-C, 133, 7, 1986, pp.397-408.

Hindi K. S., Brameller A., Design of Low-Voltage Distribution Networks: A Mathematical Programmaing Method, Proc. IEE, 124, 1, 1977, pp.54-58.

Holt Jr S.B., Crawford D.M., Distribution Sunstation Planning using optimization methods, IEEE Tutorial Course, 1976, pp.69-76.

Hongwei Dai, Yixin Yu, Chunhua Huang, Chengshan Wang, Shaoyun Ge, Optimal Planning of Distribution Substation Lacations and Sizes -- Model and Algorithm, IEEE TENCON'93 BEIJING, 1993, pp.351-354.
Hsu Y., Chen J., Distribution Planning Using a Knowledge-Based Expert System, IEEE Trans. Power Delivery, 5, 3, 1990, pp.1514-1519.

Kagan N., Adams R.N., A Computational Decision Support System for Electrical Distribution Systems Planning, IEEE, 1992, pp.133-138.

Lin W.M., Su Y.S., Tsay M.T., Genetic Algorithm for Optimal Distribution System Planning, IEEE, 1998, pp.241-245.

Masud E., An Interactive Procedure for Sizing and Timing Distribution Substations using Optimization Techniques, IEEE Trans. PAS, 93, 5, 1974, pp.1281-1286.

Masud E., Distribution Planning:state of the art and extensions to substation sizing, Elec.Power Syst. Res, 1, 1978, pp.203-212.

Mikic O.M. , Mathematical Dynamic Model for Long-term Distribution System Planning, IEEE Trans. Power System, 1, 1, 1986.

Miranda V., Ranito J.V., Proença L.M., Genetic Algorithms in Optimal Multistage Distribution Network Planning, IEEE Trans. Power System, 9, 4, 1994, pp.1927-1933.

Nara K., Satoh T., Aoki K., Kitagawa M., Multi-Year Expansion Planning for Distribution System, IEEE Trans. Power System, 6, 3, 1991, pp.952958.

Nara K., Satoh T., Kuwabara H., Aoki K., Kitagawa M., Ishihara T., Distribution Systems Expansion Planning by Multi-stage Branch Exchange, IEEE Trans. Power System, 7, 1, 1992, pp.208-214.

Nara K., State of the Arts of the Modern Heuristics Application to Power System, IEEE, 2000, pp.1279-1283.

Neimane V., Andersson G., Distribution Networks Reinforcement Planning: A Dynamic MultiCriteria Approach, IEEE, pp.260.

Peponis G.J., Papadopoulos, New Dinamic, Branch Exchange Method for Optimal Distribution System Planning, IEE Proc. On Generation, Transmission and Distribution, 114, 3, 1997, pp.333-339.

Ponnavaikko M., Prakasa Rao K.S., Optimal Distribution System Planning, IEEE Trans. PAS, 100, 6, 1981, pp.2969-2976.

Quintana W.H., Temraz H.K., Hipel K.W., Twostage Power System Distribution Planning Algorithm, IEE Proc-C, 104, 1, 1993, pp.17-29.

Ramírez-Rosado I., Gönen T., Pseudodynamic Planning for Expansion of Power Distribution Systems, IEEE Trans. Power System, 6, 1, 1991, pp.245-253.

Ramírez-Rosado I., Bernal-Agustin J.L., Genetic Algorithms Applied to the Disign of Large Power Distribution System, IEEE Trans. Power System, 13, 2, 1998, pp.696-703.

Ramírez-Rosado I., Dominguez-Navarro J., YustaLoyo J., A New Model for Optimal Electricity Distribution Planning Based on Fuzzy set Techniques, IEEE, 1999, pp.1048-1054.

Sun D.I., Farris D.R., Cote P.J., Shoults R.R., Chenn S.S., Optimal Distribution Substation and Primary Feeder Planning via the Fixed Charge 
Network Formulation, IEEE Trans. PAS, 101, 3, 1982, pp.602-608.

Tang Y., Power Distribution System Planning with Reliability Modeling nad Optimization, IEEE Trans. Power System, 11, 1, 1996, pp.181-189.

Thompson G. L., Wall D. L., A Branch and Bound model for Choosing Optimal Substations Locations, IEEE Trans. PAS, 100, 5, 1981, pp.2683-2687.

Tumazos S., Expert System / Alghorithm Based Radial Low Voltaje Distribution Network Configuration Tool, ST118.101, 1997, pp.1-9.

Skrlec D., Krajcar S., Privicevic B., Blagajac S., Exploiting the Power of Genetic Algorithm in Optimization of Distribution Networks, Procc. 8th Mediterranean Electrotechnical Conference, 1996, pp.1607-1610.

Wall D. L., Thompson G. L., Northcote-Green J.E.D., An Optimization Model for Planning Radial Distribution Networks, IEEE Trans. PAS, 98, 3, 1979, pp.1061-1065.

Wong K.P., Cheung H.N., Artificial Intelligence Approach to Load Allocation in Distribution Substations, IEE Proc-C, 134, 5, 1987, pp.357364.

Yahab Kobi, Oron Gideon, Optimal Location of Electrical Substation in Regional Energy Supply Systems, IEEE, 1996, pp.307-309.

Youssef H.K., Hackan R, Dynamic Solution of Distribution Planning in Intermediate Time Range, IEEE Trans. Power Delivery, 3, 1, 1988, pp.341-344.

Dueire Lins, Zanoni, de Carvalho Jr., M. Alfonso, An Expert System for Power Distribution Networks Feeders Planning, IEEE, 1996, pp.457-460. 


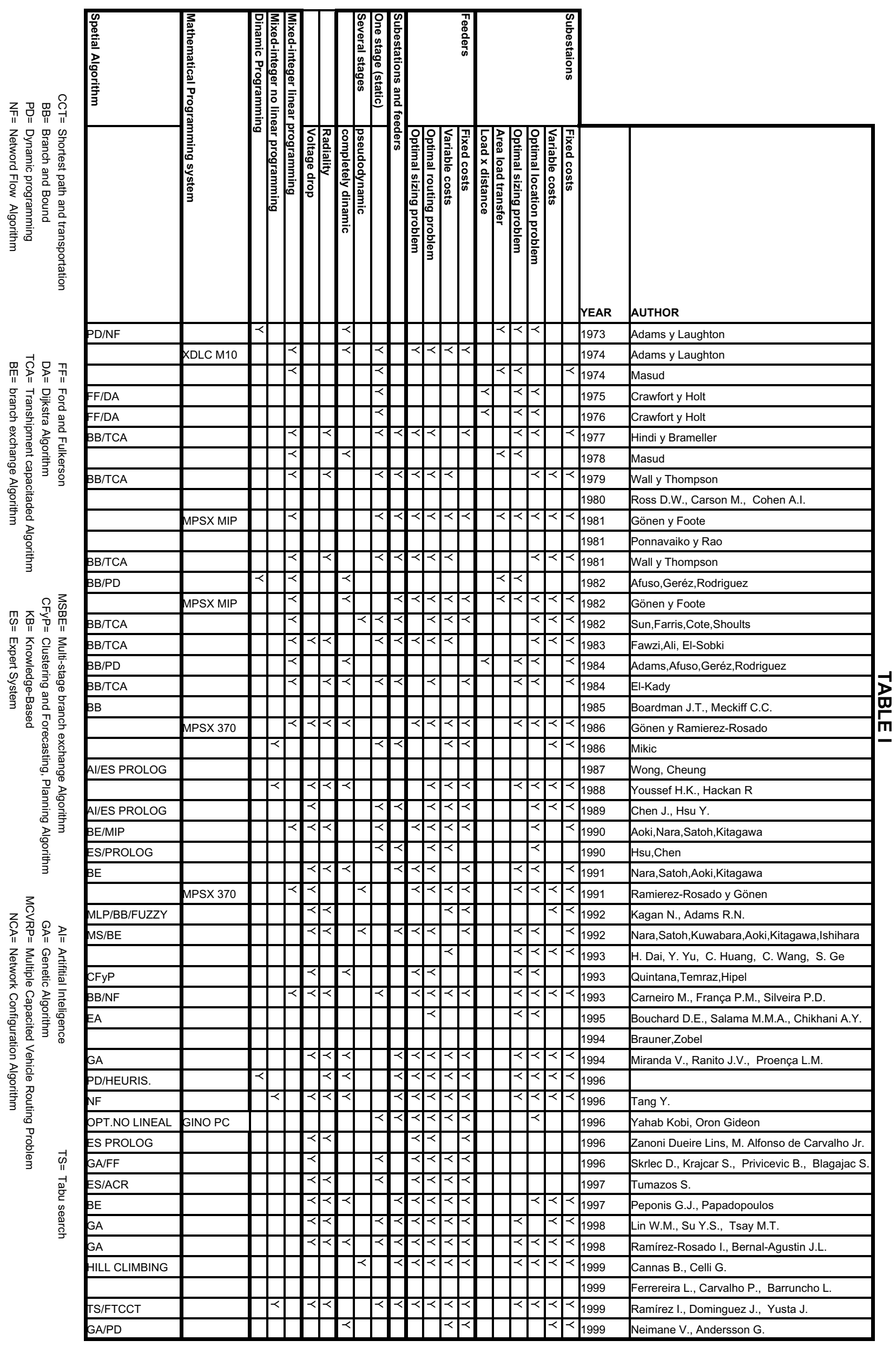

